\title{
Area-selective deposition of charged particles derived from colloidal aerosol droplets on a surface with different hydrophilic levels
}

\author{
K. Kusdianto ${ }^{1,4}$, Masao Gen ${ }^{1}$, and I. Wuled Lenggoro ${ }^{1,2,3 *}$ \\ ${ }^{1}$ Graduate School of Bio-Applications and Systems Engineering, \\ ${ }^{2}$ Department of Chemical Engineering, and ${ }^{3}$ Institute of Engineering, \\ Tokyo University of Agriculture and Technology, \\ Nakacho 2-24-16, Koganei, Tokyo 184-8588, Japan. \\ ${ }^{4}$ Department of Chemical Engineering, Institut Teknologi Sepuluh Nopember, \\ Jalan ITS Raya, 60111, Surabaya, Indonesia. \\ *Corresponding author’s E-mail: wuled.@cc.tuat.ac.jp, Tel: +81-42-3887987
}

\begin{abstract}
The effect of chemical treatment of a metallic substrate on the deposition behavior of charged aerosol particles derived from spraying droplets was investigated. A single substrate with areas having different hydrophilic levels was prepared as target surface. The treated (i.e. higher hydrophilic level) area, measured using a surface potential meter, showed a higher negative potential. A numerical simulation predicted that positively charged aerosol particles tended to approach and were subsequently immobilized on the high hydrophilic area. The area with higher hydrophilicity could collect particles with higher number concentration (density) than the other areas. The relationships were demonstrated in (i) the electrostatic surface potential, (ii) the hydrophilicity of surface, and (iii) the enhancement of adhesive force between the deposited particles and the surface.
\end{abstract}

Keywords: substrate; pattern; chemical treatment; electrostatic; surface potential 


\section{Introduction}

Particles suspended in the gas phase as charged aerosols have been regarded as an effective route for transferring the nanoparticles from the source (e.g. colloidal suspension) to a solid substrate at high deposition efficiency, without coagulation of particles (Jaworek and Sobczyk, 2008). Deposition of aerosol particles for producing nano-structured materials have been widely used in several aspects, such as biology (Kim et al., 2008), microelectronics (Deng and Gomez, 2011), biomolecular technology (Ranganath et al., 2011), environmental health applications (Jung et al., 2011), and pharmaceutical particle fabrication (Rezvanpour et al., 2012). Eventhough the relationship between the conditions of the substrate and the deposition mechanism of the charged aerosol particles is also important but there are few uncertain about this topic. The surface conditions of a substrate can be modified by changing its physical and chemical properties. Barry et al. (2003) reported that the electrostatic driven self-assembly of charged nanoparticles onto the charged surface area, where it offered a more efficient method compared with other techniques. The charged areas were generated by a technique which had used a flexible and conductive electrode to pattern electrons and holes in a thin-film electret. Xie et al. (2010) investigated a single step to generate polymeric particles with patterns of dots, circles, squares, and bands on the substrate using deposition of charged aerosol particles through a mask.

The physical effect of electrically patterned surface on the deposition of aerosol particles had been investigated by Krinke et al. (2001) and Lenggoro et al. (2006). The particles were attracted to a desired position due to the electrostatic force of particles and the "patterned" area. The charged particles could be also deposited onto a surface patterned with a photoresist controlled by introducing of ions having the same polarity together with the charged aerosol particles (Kim et al., 2006). The accumulated ions on the photoresist modified the applied field, in order to focus the nanoparticles onto the exposed parts of the patterned surface. Furthermore, Lee et al. (2011) studied patterning films of metal nanoparticles based on plasma electrochemical reduction. This approach provided fabrication for transparent, flexible and patterned films of metal nanoparticles. Our group reported for the first time the relationship between the chemical condition of surface and the efficiency of aerosol deposition, using an aluminum substrate treated by sodium hydroxide and phosphoric acid (Naim et al., 2010). In our previous studies, the whole substrate was chemically treated. Eventhough an untreated substrate had a lower number 
concentration of the deposited particle than that of the treated one, but the deposition mechanism was still uncertain. Meanwhile, the present study used phosphoric acid as an agent to create an area of the substrate which is chemically different. To understand better about the particle deposition, a half area of the substrate was treated, whereas the other area was left untreated. The research hypothesis is the chemical treatment by the phosphoric acid will alter the surface at the molecular level, under the condition that enables formation of the surface with different hydrophilicity. Furthermore, the hydrophilicity may also change the surface electric potential. In this case, we assume relationship between chemical treatment, the hydrophilicity, and the surface electric potential.

Jacobs and Stemmer (1999) measured the surface electric potential distribution using atomic force microscopy (AFM) and Kelvin probe force microscopy (KFM). They investigated the potential maps of composite metal and semiconductor films, by which differentiated the materials with resolution of a few $\mathrm{nm}$. The surface charges were detected as an image of electric surface potential. Meanwhile, Ozasa et al. (2008) made direct measurement using KFM to observe the negative values of surface potential patterns on tris(8-hydroxyquinolinato) aluminum(III) $\left(\mathrm{Alq}_{3}\right)$ thin film. The surface charges on a photoresist surface generated by corona discharge of $\mathrm{N}_{2}$ positive ions were also measured using KFM (Lee et al., 2009). In the measurements of KFM, a conductive probe is used to detect the electrostatic force generated by the potential difference between the sample surface and the probe. However, the surface electric potentials investigated in previous studies were limited to the nanometer or micrometer scale.

Our present study uses the same principle of surface electric measurement in the KFM, but we have measured the surface electric potential in a larger area with a probe diameter of about $10 \mathrm{~mm}$. The "bulk" measurement using this technique has enabled measurement of the surface electric potential of the target (i.e. half area of the substrate). We have investigated the relationship between the chemical treatment and the corresponded surface electric potential. The objective of our study is to investigate the relationship between the hydrophilic surfaces and the efficiency (or potential) of the surface to capture and immobilize the particles transported from the gas-phase.

\section{Experimental Methods}

\subsection{Preparation of materials and substrates}


Charged particles were suspended in the gas phase by aerosolization of a suspension. The suspension was composed of a mixture of $\mathrm{SiO}_{2}$ (Snowtex, Nissan Chemical Industries Co. Ltd., Tokyo) and $\mathrm{AgNO}_{3}$ salt (Wako Pure Chemical Industries Co. Ltd., Tokyo). Firstly, $\mathrm{SiO}_{2} 40 \%$ wt with a mean diameter of 70-100 nm (primary particle, the value given by the maker) was dispersed in a solvent mixture of water:ethanol (75:25\%wt/wt) in order to make $\mathrm{SiO}_{2}$ of $0.1 \%$ wt. A salt $\mathrm{AgNO}_{3} 0.1 \mathrm{M}, 0.3 \%$ wt of total weight solution, was added into $\mathrm{SiO}_{2}$ suspension in order to amplify the possibility of detection using X-ray fluorescence method (XRF, JSX 3100 RII, JEOL, Tokyo), because the heavier element (Ag) is more easily detectable than $\mathrm{Si} . \mathrm{H}_{3} \mathrm{PO}_{4}$ (Wako Pure Chemical Industries) was used for substrate treatment by dilution into a ultra-pure water sample to obtain $0.1 \mathrm{M}$ in concentration. All chemicals were used as received without further purification. Particlesize distributions in the liquid phase were measured using an analysis of dynamic light scattering (DLS) (HPPS 5001, Malvern Instrument, Worcestershire), and the average particle diameter was $623 \mathrm{~nm}$. The conductivity and $\mathrm{pH}$ of the suspension measured by a conductivity meter (CM-21P, TOA-DKK, Tokyo) and a pH meter (Orion 920Aplus, Thermo Electron Corporation, Tokyo) at $25{ }^{\circ} \mathrm{C}$ and the results were $32.3 \times 10^{-3} \mathrm{~S} / \mathrm{m}$ and 2.96, respectively. The suspension was ultrasonicated $(35 \mathrm{kHz})$ within $15 \mathrm{~min}$ in order to prevent fouling on the wall surface of the container and further aggregation during storage.

An aluminum sheet with $25 \mathrm{~mm}$ diameter and $0.02 \mathrm{~mm}$ thickness was used as a model substrate. The substrates were treated in the following sequence steps: (i) submerged about half of the substrate (12.5 mm of height) into $\mathrm{H}_{3} \mathrm{PO}_{4}$ solution for $10 \mathrm{~min}$, (ii) submerged with ultra-pure water for $10 \mathrm{~min}$, and (iii) dried in an oven at $120{ }^{\circ} \mathrm{C}$ for $1 \mathrm{~h}$. The treated and dried substrates were kept in a desiccator before the deposition experiments. It was important to use a single aerosol generator for a single experiment in order to investigate the other parameters of a substrate, such as a treated or untreated area. The surface electric potential values of the treated and untreated areas (before the deposition process) were measured by a non-contact surface potential meter (Model 323, Trek, New York) as -590 and $-260 \mathrm{mV}$, respectively. The size (diameter) of the probe was $10 \mathrm{~mm}$, which cover the measured surface. The chemical elements of the substrate, analyzed before the treatment using the X-ray fluorescence method, were $\mathrm{Al}(99.18 \%), \mathrm{Fe}(0.68 \%)$, Ti (0.04\%), V $(0.04 \%)$, and Zn (0.06 \%). The X-ray diffraction (XRD, RINT2100VPC/N, Rigaku, Tokyo) and the micro-Raman spectroscope (Nicolet Almega XR Thermo Electron, 
Barrington) were also used to obtain more information on the crystal structure and the molecular conditions of the surface before and after the treatment.

\subsection{Experimental}

\subsubsection{Experimental setup and observation}

The experimental setup was performed using a laboratory-made electrospray device, where a stainless steel (SUS 304) capillary tube with $0.1 \mathrm{~mm}$ inner diameter and $0.25 \mathrm{~mm}$ outer diameter was connected with a DC power supply with a positive polarity of $3.0 \mathrm{kV}$. The suspension was pumped through the capillary with a rate of $7.1 \mathrm{~mm} / \mathrm{s}$. The substrate was positioned perpendicularly from the capillary tip, where the distance between the tip and the substrate was set to 70 or $120 \mathrm{~mm}$. These two distances provided different times for droplet evaporation during their transportations onto the substrate; $120 \mathrm{~mm}$ was expected to generate "drier" deposition. After preliminary experiments, the spraying time was set at $30 \mathrm{~min}$. The metal ring with $24 \mathrm{~mm}$ diameter, connected to the grounded electrode, was placed in front of the capillary tip $(20 \mathrm{~mm})$ to stabilize the electrospray towards the mounted aluminum substrate.

Liquid cone-jet formation was verified visually using an optical microscope. In order to ensure the stability, the generated current was also recorded by connecting an electrometer ( $\mathrm{R}$ 8240, Advantest, Tokyo) to the grounded electrode (except for nongrounded substrates). The experimental setup was carried out by using grounded and nongrounded electrodes and placed inside a chamber with controlled humidity, temperature and wind velocity. An electric heater equipped with a small fan (FE 06UIJ, National, Osaka) was placed $150 \mathrm{~mm}$ under the apparatus in order to investigate the effect of ambient temperature on the deposition process. In spite of measuring the gas velocity, an anemomaster probe 6141 (Kanomax, Osaka) was placed at various distances and perpendicular to the substrate and the heater (Fig. 1). The measured velocity rate is also shown in Fig. 1. The results showed no significant difference for velocity in front of the capillary toward the substrate. A cylinder netting-mesh, with $120 \mathrm{~mm}$ ID and $150 \mathrm{~mm}$ OD, was used to place silica gels and set a surrounding electrospray device to adsorb water vapor.

The temperature surrounding the substrate was measured by a non-contact infrared thermometer (IT-550 Horiba, Kyoto). The average temperature during the experiment was $20.4{ }^{\circ} \mathrm{C}$, and increased up to $35.0{ }^{\circ} \mathrm{C}$ after turning on the heater. 
A schematic diagram of the entire system is shown in Fig. 1. The sessile drop technique was used to measure the contact angle; a $5 \mu \mathrm{L}$ drop of ultra-pure water was dropped on the sample surface at $20{ }^{\circ} \mathrm{C}$. A digital camera was used to record the formation of a water droplet forming an "equilibrium" dome on the horizontal surface..

\subsubsection{Characterization}

By consideration of the possible influence of the ambient pressure on the contact condition between the particles and the surface, some instruments based on atmospheric or lower pressures were used to characterize the samples. In the case of low pressure type analysis, field emission scanning electron microscopy (FE-SEM, JSM 6335F, JEOL, Tokyo) and scanning electron microscopy (SEM, JSM 6510, JEOL) were used to observe the morphology of the surface. To deposit a conductive coating for pre-treatment of scanning electron microscopy sample preparation, the Pt-based ion sputtering device (JFC1100 , JEOL, operated at $1.2 \mathrm{kV}$ and $6.5 \mathrm{~mA}$ ) was used for $1 \mathrm{~min}$ for three times. The state of the deposited particles was analyzed using an image-processing software (WinRoof, Mitani, Tokyo).

The XRF method, with tube voltage of $50 \mathrm{kV}$ and $1 \mathrm{~mA}$, was used to investigate the chemical elements of the surfaces (mainly, $\mathrm{Ag}$ and $\mathrm{Si}$ ) under $1 \mathrm{~atm}$. Furthermore, the XRD method was used to obtain the crystal structure of the surface, with a scan speed of $5 \% \mathrm{~min}$ and a sampling point of $0.01^{\circ}$ using a CuK $\alpha$ radiation source, $\lambda=1.5406 \AA$. Another atmospheric pressure type analysis technique, is Raman spectroscopy, which was used to identify the molecular information on the surface.

\subsubsection{Numerical simulation}

Electric fields of the system were studied by numerical simulations using a finiteelement based software (COMSOL Multiphysics Ver.4.3, Stockholm). The velocity along particle trajectory was estimated using a differential equation of the electrostatic force,

$$
\mathrm{d}\left(m_{\mathrm{p}} V\right) / \mathrm{d} t=F_{\mathrm{t}}
$$

where $m_{\mathrm{p}}, V$, and $F_{\mathrm{t}}$ are the mass and velocity of the particles and the electrostatic force, respectively. Furthermore, the electric fields formed by the positive polarity of applied voltage and surface (measured by the surface potential meter) are governed by Poisson's equation.

$$
-\nabla x\left(\sigma \nabla V-\boldsymbol{J}^{\mathrm{e}}\right)=\mathrm{d} Q_{j}
$$

Where $V, x, \sigma, \boldsymbol{J}^{\mathrm{e}}$, and $Q_{j}$ are the electric potential, thickness, charge density, externally generated current density, and the electric charge, respectively. By inserting the $V$ values 
of the treated and untreated areas $(-590$ and $-260 \mathrm{mV})$ and setting the substrate with and without grounding of each surface, where the electric field has been investigated numerically.

\section{Results and discussion}

\subsection{Characterization of surface conditions}

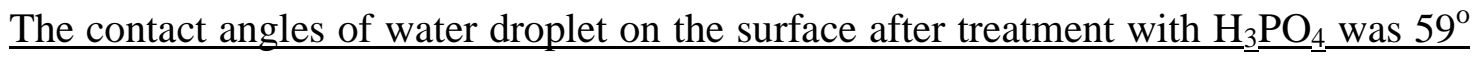
and without treatment was $82^{\circ}$, respectively. These angles were measured as the angle formed by the solid surface and the tangent line to the upper surface at the end point (Kwok and Neumann, 1999). The contact angle of the treated area, was lower than the untreated area. It was implied that the treated substrate was more hydrophilic. This contact angle depends on the two major factors: chemical functionality and/or surface "roughness" (Eustathopolos et al., 1999). In addition, there was no difference between the contact angles of water droplet on the substrates before and after deposition of particles. This indicates that the structures (or numbers) of the particles deposited on the surface do not influence the measured contact angles.

The FE-SEM images (down to the level of few $\mathrm{nm}$ ) of the treated and untreated areas showed no significant difference (Fig. 2). It means that the physical differences based on surface roughness (few nm-based) can be ruled out for forming the "hydrophilic" surface. We assume the hydrophilic surface is from chemical functionality of the phosphoric acid. The XRF analysis detected the chemical element of $\mathrm{P}$ on the treated substrate with a mass value of $0.1 \%$ and a peak at $2.02 \mathrm{keV}$. This peak originates from the phosphate. On the other hand, the chemical element of $\mathrm{P}$ was not found on the untreated substrate. These results were also supported by analysis in Raman spectroscopy (Fig. 3), which showed significant difference between the treated and untreated substrate spectra. In the treated area showed two bands at 1590 and $1320 \mathrm{~cm}^{-1}$, which are assigned to the $\left(\mathrm{PO}_{4}\right)^{3-}$ stretching (Frost et al., 2006) and $\mathrm{P}=\mathrm{O}$ stretching vibrational modes (Mogus-Milankovic et al., 2001), respectively. Meanwhile, there are no phosphate peaks were observed of these bands on the untreated area. The $\mathrm{P}=\mathrm{O}$ stretching vibration is related to the formation of aluminum methaphosphate. Rotole and Sherwood (2001) proposed that the reaction of aluminum with phosphoric acid forms aluminum methaphosphate bonded directly onto the metal surface. There was no difference in the peak position of the XRD spectra before and 
after the treatment. This indicates that the chemical treatment forms a thin layer on molecular levels but not a crystalline structure on the surface.

\subsection{Effect of controlling humidity on the particle deposition}

The sufficiently stable condition for generation of a liquid cone was found by application of DC voltage of $3 \mathrm{kV}$ at a velocity rate of $7.1 \mathrm{~mm} / \mathrm{s}$. Smith (1986) proposed an equation for the potential, $V_{\text {on }}$, that required for the onset of electrospray,

$$
V_{\text {on }} \approx\left[r_{\mathrm{c}} \gamma \cos \theta / 2 \varepsilon_{0}\right]^{1 / 2} \ln \left(4 l / r_{\mathrm{c}}\right)
$$

where $\gamma, \varepsilon_{0}, r_{c}, \theta$, and $l$ are the surface tension of the solvent, the permittivity of vacuum, the radius of capillary, the half angle of the Taylor cone, and the distance between the capillary tip and the substrate, respectively. In the present experiment, we inserted the parameter values, $\varepsilon_{0}=8.8 \times 10^{-12} \mathrm{C}^{2} / \mathrm{J}, \theta=49.3^{\circ}$ (Taylor, 1965); and $\gamma=36.09 \times 10^{-3} \mathrm{~N} / \mathrm{m}$ (Vazques et al., 1995), and $V_{\text {on }}=3.1 \mathrm{kV}$, which is found to be slightly higher than the applied voltage, $3.0 \mathrm{kV}$. The use of a solvent mixture (water:ethanol) was subjected to reduce the surface tension in order to enhance the stable generation of a liquid jet. It is because droplet formation in an electrospray process is influenced by the hydrostatic balance between the electrostatic force and the surface tension (Lenggoro et al., 2000). On the other hand, ethanol was used to enhance the solvent evaporation after spraying, because its boiling point is lower than that of water.

Figure 4 shows the SEM images of particles deposited on the treated and untreated areas by placing a dryer system based on silica gel beads surrounding a space between the aerosol generator and the grounded substrate. The SEM images showed that the treated area has a higher number concentration of the deposited particles than the untreated one. However, a small number of aggregated particles (around $6 \mu \mathrm{m}$ ) were also deposited on the untreated area. This phenomenon indicates that, the potential for deposition of the charged particles transported toward the substrate might be increased due to the reduction of water vapor in the gas phase by introducing a silica gel dryer system. The relative humidity was decreased from the initial condition of $65 \%$ to $47 \%$ after addition of silica gel. Lo et al. (1999) reported that the deposition velocity increased with decreasing relative humidity. The surface electric potential of the treated area was higher than the untreated one, therefore more particles deposited on the treated area than the untreated area. In addition, the electrometer detected a higher value after the addition of silica gel dryer (3.4 
$\mathrm{nA})$ than that without the dryer $(0.8 \mathrm{nA})$. This finding indicates that more charged particles were deposited under the condition of lower humidity.

In order to study the effect of controlling humidity on the deposition, we used an electric heater and removed the silica gel dryer from the experiments. Figure 5 shows the particles deposited under this "hot" and "wet" condition. It shows that most of the particles were deposited on the treated area instead of untreated ones (Fig. 5a). In contrast, no particles were observed on the untreated area (Fig. 5c). The absence of silica gel hindered immediate removal of water vapor in the path. This condition then inhibits the aerosol transport toward the substrate, providing the deposition time on the treated area due to the electrostatic force. These phenomena can be ascribed to a difference in the surface electric potential. Based on the measured potential value, the treated area was found to be more negatively charged than the untreated area. It may cause the positively charged aerosols attracted to the treated (more hydrophilic) area with higher electrostatic force. Furthermore, most of the deposited particles on the surface were aggregated to one another (Figs. 5b and c).

\subsection{Effect of ambient temperature on the particle deposition}

For this purpose, an experiment was carried out by turning off the heater. The silica gel dryer was not installed in this case. It was observed that most of particles were deposited on the treated area of the substrate (Fig. 6a), while no deposited particles were observed on the untreated area (Fig. 6b). These phenomena happened because the attraction between the positively charged aerosols and the negatively charged surfaces, as mentioned in 3.2. The negatively charged surface was attributed to the phosphoric acid that was incorporated in the aluminum surface (Fig. 3). Hennemann and Brockmann (1981) reported negative potential in sulfuric acid anodized aluminum surface. Phosporic acid which is a strong acid, should have the same tendency as the sulfuric acid to form a negatively charged surface. Moreover, incorporation of phosphoric acid on the treated substrate may enhance the interaction between the surface and the incoming positively charged aerosols.

Another mechanism which may explain our observation is the chemical adsorption of charged aerosols on the treated surface. Adhesion by its chemical adsorption is attributed to the surface chemical force and to the chemisorption and physisorption of atomic and molecular species (Allen, 1993). Carre and Schultz (1983) reported that the surface treatment of aluminum by phosphatization gave higher adhesion compared with the untreated substrate. In order to attain strong adhesion, the adhered surface should be kept 
free from an organic film with low surface tension, on which Baier et al. (1968) predicted that substituent groups such as $-\mathrm{OH},-\mathrm{SH},-\mathrm{COOH}$, and $-\mathrm{NH}_{2}$ at the outermost surface would increase its adhesion by increasing the surface energy, whereas less polar groups such as $-\mathrm{CH}_{3}$ - or $-\mathrm{CH}_{2}$ - would decrease the adhesion on the surface. Moreover, aluminum treated with $\mathrm{H}_{3} \mathrm{PO}_{4}$ was expected to provide the $\mathrm{P}-\mathrm{O}$ framework on the surface of the substrate (Naim et al., 2010); then $\left[\mathrm{PO}_{4}\right]^{3-}$ ions can provide more P-O interaction chains between the treated surface and $\mathrm{SiO}_{2}$ particles.

The FE-SEM image shows the interface (border) between the treated and untreated areas (Fig. 6c). The detailed morphology of the deposited particles is shown in Fig. 6d. Most of the particles were deposited as a monolayer. The average size of the deposited particles analyzed by the image analysis software was $\sim 83 \mathrm{~nm}$ (Fig. 6e). The sizes of the secondary particles up to $171 \mathrm{~nm}$ were also observed as evidence that the aggregation also occurred. The size distribution of the particles also indicates that most of the particles were deposited in primary condition $(70-100 \mathrm{~nm})$.

\subsection{Effect of grounding on the particle deposition}

In order to make better understanding of the deposition phenomena, other experiments were also carried out by setting the metallic substrate without connection to the grounded electrode. The supplying rate of the spraying liquid and the distance between the capillary tip and the substrate were kept constant. The particles deposited on the treated and untreated areas of the substrate show the same tendency (based on the number concentration) as the experiments in the presence of grounding (Fig. 7a). Most of the particles were deposited on the treated area, but no interface (between the treated and untreated areas) was clearly indicated in comparison to that of the grounded experiment. No deposited particles were detected on the untreated area (Fig. 7c), meanwhile there are more particles were deposited on the treated area in the presence of the grounded than that of the ungrounded. This may be attributed to the decreasing electric fields on the substrate under the ungrounded condition. The decrease in the electric fields may decrease the electrostatic interaction between the surface and the charged aerosols and decrease the Coulomb force, so as to decrease the attraction force between the charged aerosols and the surface.

\subsection{Estimation of the droplet size and its evaporation time}


For discussion on the droplet (or particle) size, Hartman et al. (2000) and Ganan-Calvo (1999) proposed equations to estimate the initial size of sprayed droplets, as shown in Eqs. (4) and (5), respectively.

$$
\begin{aligned}
& d_{\mathrm{d}}=\left(\rho \varepsilon_{0} Q^{3} / \gamma K\right)^{1 / 6}=d_{0} k_{\mathrm{d}}\left(Q / Q_{0}\right)^{1 / 2} \\
& d_{0}=\left(\pi^{-2} \gamma \varepsilon_{0} \rho^{-1} K^{-2}\right)^{1 / 3},
\end{aligned}
$$

where $d_{\mathrm{d}}, \rho, Q, \gamma$, and $K$ are the droplet size from the current scale law, the liquid density, the liquid flow rate, the liquid surface tension, and the liquid conductivity, respectively. The constant $k_{\mathrm{d}}=2.9$ is assumed to be independent of liquid permittivity. By inserting the value of these parameters, the estimated droplet size is between 1.1 and $1.4 \mu \mathrm{m}$. However, based on the deposited aggregate size (Fig. 7a), the estimated average droplet size was $52 \mu \mathrm{m}$. This large size indicates that the deposition of aerosols occurred under wet condition (as coagulation of droplets).

This finding is supported by observation of the particle morphologies displayed in Figs. $7 \mathrm{~b}$ and $\mathrm{d}$, in which most of the particles were assembled on the ring edge, whereas a few particles were scattered in the center such as the "coffee ring" phenomenon (characteristic ring-like deposition along the perimeter of a spill of coffee, Deegan et al. 1997). Wet condition may be caused by a deposition at a short distance $(\sim 70 \mathrm{~mm})$, where the aerosol droplets were not completely evaporated before their arrival at the substrate. The particles then spread along the hydrophilic surface. Because the flux distribution along the "liquid film" formed in the surface was not uniform and the evaporation rate is larger at the edge than that of the center, most of the particles were aggregated on the edge (Deegan et al., 2000).

The time required for a single droplet of a given size to evaporate completely was calculated using empirical equations (Hinds, 1999), as described in Eqs. (6)-(8).

$$
\begin{aligned}
& t=R \rho d_{\mathrm{d}}^{2} /\left[8 D_{v} M\left(p_{\mathrm{d}} / T_{\mathrm{d}}-p_{\infty} / T_{\infty}\right)\right] \\
& T_{\mathrm{d}}-T_{\infty}=\frac{\left(6.65+0.345 T_{\infty}+0.0031 T_{\infty}^{2}\right)\left(S_{\mathrm{R}}-1\right)}{1+\left(0.082+0.00782 T_{\infty}\right) S_{\mathrm{R}}} \\
& p_{\mathrm{d}}=\exp \left[16.7-4060 /\left(T_{\mathrm{d}}-37\right)\right]
\end{aligned}
$$

where $t, \rho, R, d_{\mathrm{d}}, D_{v}, M, p_{\mathrm{d}}, p_{\infty}, p_{\mathrm{d}}, T_{\mathrm{d}}, T_{\infty}$ and $S_{\mathrm{R}}$ are the time required for a droplet to evaporate completely, density, gas constant, droplet diameter, diffusion coefficient of vapor in air, molecular weight, partial vapor pressure at the droplet surface, partial vapor 
pressure at the droplet surface, saturation vapor pressure, temperature at the droplet surface, temperature away from the droplets, and the saturation ratio, respectively. It is clear that the evaporation rate is linearly proportional to the droplet diameter. Due to the limitation to measure the droplet size under the real condition, we used the value that estimated by Ganan-Calvo, $1.4 \mu \mathrm{m}$, for measuring the evaporation rate in Eq. (6). To estimate the saturation vapor pressure in Eq. (8), we inserted $T_{\mathrm{d}}$ values in Eq. (7). Finally, the time required for evaporation of a single droplet was estimated to be 1.0 and $0.6 \mathrm{~ms}$ at $T_{\infty}=20.4$ and $35.0{ }^{\circ} \mathrm{C}$, respectively.

The micrometer size of the deposited aggregate particles on the surface suggests that the deposition of droplets neither occurs as single particles nor as aggregates. The aggregation mechanism of the particles on the edge is described in Fig. 8. The droplets aggregated on the surface to create a "liquid film" on the surface and form a "coffee ring" pattern. Meanwhile, Park and Moon (2006) reported that the large droplet ( $\sim 50 \mu \mathrm{m})$ was able to spread along the hydrophobic surface. The average diameter of the dried particles (structures) grew up to $140 \mu \mathrm{m}$ after their impaction. The spread of the particles on the hydrophilic surface should be more effective than that of a hydrophobic surface. On the other hand, charged particles may have contributed to the reduction of the evaporation rate, because the rate of evaporation of a charged droplet was slower than that of an uncharged droplet of the same size (Bhalwankar et al., 2004).

This experiment was also carried out at "hot" ambient $\left(35.0{ }^{\circ} \mathrm{C}\right)$ by setting the distance between the capillary tip and the substrate at $120 \mathrm{~mm}$ in order to perform "dryer" deposition. Figure 9a shows that most particles were deposited on the treated area without showing a wet-deposition (e.g. "coffee ring" phenomenon). The aggregate particles at the edges, as shown in the "wet" deposition $(70 \mathrm{~mm})$, were not observed at $120 \mathrm{~mm}$. It indicates that "dry" deposition could be attained by setting a longer distance between the capillary tip and the substrate. The interface (boundary) of the deposited particles between the treated and untreated areas was not clearly observed, because no deposited particle appeared on the untreated area (Fig. 9b).

\subsection{Investigation of the concentration of particle deposited by XRF method}

XRF method was used to measure the bulk (mm scale) concentration of the target elements ( $\mathrm{Si}$ and $\mathrm{Ag}$ ) in the deposited particles to confirm the existence of $\mathrm{SiO}_{2}$ particles and $\mathrm{AgNO}_{3}$ (salt) at normal pressure (1 atm). Figure 10 shows the corresponding numberconcentration of the deposited particles on the treated area calculated by the integrated area 
of XRF spectra of Si. Particles of the highest number were observed when the substrate was connected to the grounded electrode with additional heating. In contrast, the number decreased when the substrate was not grounded. As mentioned above, decreasing electric fields cause a decrease in the electrostatic force between the surface and the charged aerosols, so that the attractive force among them is weakened. The existence of the $\mathrm{Ag}$ element in the deposited particles was also analyzed, but the weakness of its intensity hindered a reliable comparison.

\subsection{Particle deposition in the absence of Ag salt}

Using the experimental setup stated in the last section, a series of experiments were carried out using $\mathrm{SiO}_{2}$ nanoparticles without adding $\mathrm{AgNO}_{3}$ salt. The average particle size in the liquid phase (300 nm, measured by DLS) decreased in the absence of $\mathrm{AgNO}_{3}$. Figure 11 shows the $\mathrm{SiO}_{2}$ particles deposited on the grounded substrates. It was clearly observed that more particles were deposited on the treated area (higher hydrophilicity), and the particle sizes are larger than those of other area (lower hydrophilicity). The particle size is inversely proportional to the electrical migration velocity, $V_{\mathrm{e}}$, as (Seinfeld and Pandis, 1998),

$$
V_{e}=B_{\mathrm{e}} E=\left(q C_{\mathrm{e}} / 3 \pi \mu d_{\mathrm{p}}\right) E,
$$

where $B_{\mathrm{e}}, E, q, C_{\mathrm{c}}, \mu$ and $d_{\mathrm{p}}$ are the electrical mobility of a charged particles, electric field, electric charge, slip correction factor, viscosity, and the particle diameter, respectively.

The slip correction factor $\left(C_{\mathrm{c}}\right)$ increases with a decrease in the particle diameter $\left(d_{\mathrm{p}}\right)$. This implies that the velocity of electric migration also increases, because it is linearly proportional to the slip correction factor, and causes a faster flow of the particles toward the substrate overcoming all resistance. The treated area with higher hydrophilicity has higher negative charge, and it may enhance the electrostatic force between this surface and the incoming positively charged particles. Therefore, most of the particles were attracted toward this area, and this condition may cause the impaction of the droplets on the surface occur in "wet" condition. More hydrophilic surface allows higher "spreading speed" of the droplets on the surface. This mechanism can be used for interpretation of the deposition of larger particles on the area with higher hydrophilicity.

\subsection{Numerical simulation}

Numerical simulation was used to study the electric field of the surface for aerosol deposition. The boundary conditions of the simulation are: electric insulation of the chamber $\left(1000 \times 1000 \mathrm{~mm}^{2}\right)$, the applied voltage of a nozzle $(+3000 \mathrm{~V})$ with a diameter of 
$0.1 \mathrm{~mm}$, the treated and untreated areas (12.5 mm with surface potentials of -590 and -260 $\mathrm{mV}$, respectively), and electrical-grounding of a metal ring for stabilization droplets. Figure 12 shows the electric field patterns for "macro" $(\sim 30 \mathrm{~mm})$ and "micro" $(\sim 3 \mathrm{~mm})$ ranges. The electric patterns were clearly changed with an interface between two areas of the substrate for the "micro" range. The charged particles are expected to follow the electric fields line due to increasing of the Coulomb force. The change in the electric field direction is related to the enhancement of the electrostatic force of the treated area due to the higher negatively charged surface. The Brownian motion can be ignored when the particles approached the electrostatic patterned region generated by accumulation of ions. This is because the particle kinetic energy due to electric field was dominant. In addition, focusing of charged particles without random deposition on the patterned surface can be achieved (Kim et al., 2006).

$\underline{\text { In the present study, the electric fields on substrate with two different surface }}$ potentials (different hydrophilic levels) were numerically simulated, and the values are $25.8 \mathrm{kV} / \mathrm{m}$ (high hydrophilicity) and $15.7 \mathrm{kV} / \mathrm{m}$ (low hydrophilicity). Potential different of $10.1 \mathrm{kV} / \mathrm{m}$ was possible to induce more charged particles to be approached towards the more hydrophilic area. These phenomena are ascribable to the deposited particles, and were also supported by SEM images.

\subsection{Estimation of the particle deposition velocity near the substrate}

Particle deposition can be attributed to different mechanisms based on the deposition velocity. The velocity value as calculated with consideration of gravitational, aerodynamic, diffusion, and electrostatic effects. Empirical equations (Hinds, 1999) were used to calculate the gravitational and the electrostatic deposition velocities. Meanwhile, the estimation of the aerodynamic deposition and the diffusion velocities were calculated using equations that reported by Tammet et al. (2001). The values of the mass of particle

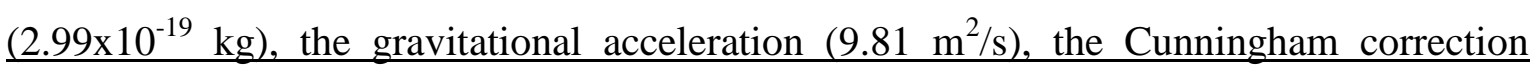
factor (3.47), and the mechanical mobility $\left(2.45 \times 10^{11} \mathrm{~m} / \mathrm{N} . \mathrm{s}\right)$ will be inserted in the equations. Then we obtained the gravitational $\left(7.19 \times 10^{-7}\right)$, the diffusion $\left(2.62 \times 10^{-6}\right)$, and the aerodynamic deposition $\left(1.27 \times 10^{-8}\right)$ velocities.

The electrostatic deposition velocity indicates the migration velocity of a charge particle in a given electric field $(\mathrm{Ve})$ can be calculated using Eq. 10, which simplify from the Eq. 9.

$$
\underline{V e}=q E B \quad(10)
$$


$\underline{B}$ is the mechanical mobility. The charge particle/mass $(2.85 \mathrm{C} / \mathrm{kg})$ was obtained by dividing the current $\left(1.5 \times 10^{-7} \mathrm{~A}\right)$ to the flow rate $\left(5.5 \times 10^{-11} \mathrm{~m}^{3} / \mathrm{s}\right)$ and the density $(949$ $\left.\mathrm{kg} / \mathrm{m}^{3}\right)$. The charge particle $\left(3.88 \times 10^{-15} \mathrm{C}\right)$ was obtained by multiplying the charge particle/mass and the mass of the corresponding droplet. Meanwhile, the value of the electric field $\left(25.8 \times 10^{-3} \mathrm{~V} / \mathrm{m}\right)$ was obtained by the numerical simulation. By inserting electric field values, the electrostatic deposition velocity were equal to 24.6 (high hydrophilicity) and $15 \mathrm{~m} / \mathrm{s}$ (low hydrophilicity). These results indicate higher probability of charged particles deposited on the area with high hydrophilicity. Moreover, the electrostatic velocity is higher than the gravitational, the diffusion, and the aerodynamic deposition velocities. These velocities indicated that the electrostatic force is dominant during deposition. Increasing of the electrostatic force between the charged particles and the "patterned" area produced nanoparticle focusing onto the desired position of the surface (Lenggoro et al., 2006).

\subsection{Mechanism of the particle deposition}

All conditions in our experimental results show that the more hydrophilic area has higher number concentration of the deposited particles. In our chemical treatment, the use of phosphoric acid may have changed the molecular level of the surface to be hydrophilic. The hydrophilic area can be acted as a "water trap". Moreover, the surface electric potential can also be altered by the chemical treatment. During the deposition, positively charged aerosols are initially attracted to the area driven by the electrostatic force caused by the "higher" negative charges. Also, the hydrophilic interaction between the particles and the surface can be enhanced (Naim et al., 2010). The more hydrophilic area may provide higher surface energy and increase the adhesion force with the particles.

The mechanism of the particle deposition in the absence and presence of the dryer system based on silica gel beads might also be proposed (Fig. 13). When the dryer system is installed (Fig. 13a), the water molecules evaporated during the transportation of droplets are immediately adsorbed by silica gels. It might increase the driving force that accelerates aerosols toward substrates. The aerosols arriving on the substrate may still be in "wet" condition. In the case of more hydrophilic area, the "speed" of the droplet spreading should be higher than that of less hydrophilic area. The reason why (aggregated) particles with different sizes have been observed in both areas may be ascribed to this interpretation. In the absence of the dryer system (Fig. 13b), the evaporated water molecules are not immediately absorbed. Therefore, the motion of particles toward the substrate would be 
inhibited. On the other hand, the charged aerosol particles can be attracted more strongly in the more hydrophilic area, with higher electric potential. We found the relation between passive surface and the active (dynamic) charged aerosol. This relation is important for aerosol deposition with controlled surface charge and electric field.

\section{Conclusion}

The effect of the hydrophilicity of a chemically treated (using phosphoric acid) metallic substrate has been studied in the deposition of charged aerosols derived from the suspension of nanoparticles. Using a single substrate with different hydrophilic levels as deposition targets, more particles were deposited on the area with higher hydrophilicity than that of the lower one. The chemically treated area formed a wider hydrophilic surface, where it was possible to increase hydrophilic interaction between the droplets and the substrate. Furthermore, "higher" negative charges produced by the chemical treatment enhanced the adhesion force between phosphate and charged aerosols due to an increase in the surface energy. The attractive forces between the negative charge on the more hydrophilic surface and the positive charge of the particles were found to play an important role in the deposition due to the electrostatic forces among them.

\section{Acknowledgements}

The authors are grateful to Drs. H. Kamiya, M. Iijima, M. Tsukada and Mr. Y. Yamada, for their supports and to Dr. K. Kuchitsu and Ms. M. P. Khairunnisa for English editing. The present study has been supported in part by the Special Condition Funds for Promoting Science and Technology from the Japan Science and Technology Agency (JST), a Grant-in-Aid for Scientific Research from the Japan Society for Promotion of Science (JSPS) No. 23560904, 23246132, 26420761, and Grants-in-Aid for Scientific Research on Innovative Areas from the Ministry of Education, Culture, Sports, Science and Technology (MEXT) No. 20120010. The Doctoral Program Scholarship for K. Kusdianto has been awarded by the Ministry of Education and Culture, Republic of Indonesia. 


\section{References}

Allen, K.W. (1993) Some reflections on contemporary views of theories of adhesion, International Journal of Adhesion and Adhesives, 13, 67-72

Baier, R.E., Shafrin, E.G., and Zisman, W.A. (1968) Adhesion: mechanisms that assist or impede it, Science, 162, 1360-1368

Barry, C.H., Lwin, N.Z., Zheng, W., and Jacobs, H.O. (2003) Printing nanoparticle building blocks from the gas phase using nanoxerography, Applied Physics Letters, 83, $5527-5529$

Bhalwankar, R.V., Sathe, A.B., and Kamra, A.K. (2004) The evaporation of the charged and uncharged water drops suspended in a wind tunnel, Proceedings of the Indian Academy of Science (Earth and Planetary Sciences), 113, 129-138

Carre, A. and J. Schultz, J. (1983) Polymer-Aluminium adhesion. I. The surface energy of aluminium in relation to its surface treatment, Journal of Adhesion, 15, 151-161

Deegan, R.D., Bakajin, O., Dupont, T.F., Huber, G., Nagel, S.R., and Witten, T.A. (1997) Capillary flow as the cause of ring stains from dried liquid drops, Nature, 389, 827-829

Deegan, R.D., Bakajin, O., Dupont, T.F., Huber, G., Nagel, S.R., and Witten, T.A. (2000) Contact line deposits in an evaporating drop, Physical Review E, 62, 756-765

Deng, W.W. and Gomez, A. (2011) Electrospray cooling for microelectronics, International Journal of Heat and Mass Transfer, 54, 2270-2275

Eustathopolos, N., Nicholas, M.G., and Drevet, B. (1999) Wettability at high temperatures, (pp. 22) Pergamon.

Frost, R.L., Musumeci, A.W., Kloprogge, J.T., Adebajo, M.O., and Martens, W.N. (2006) Raman spectroscopy of hydrotalcites with phosphate in the interlayer: implications for the removal of phosphate from water, Journal of Raman Spectroscopy, 37, 733-741

Ganan-Calvo, A.M. (1999) The surface charge in electrospraying: its nature and its universal scaling laws, Journal of Aerosol Science, 30, 863-872

Hartman, R.P.A., Brunner, D.J., Camelot, D.M.A., Marijinessen, J.C.M., and Scarlett, B. (2000) Jet break-up in electrohydrodynamic atomization in the cone-jet mode, Journal of Aerosol Science, 31, 65-95

Hennemann, O.D., and Brockmann, W. (1981) Surface morphology and its influence on adhesion, Journal of Adhesion, 12, 297-315 
Hinds, W.C. (1999), Aerosol Technology: Properties, Behavior, and Measurement of Airborne Particles, (pp. 46-47 and 278-322) John Wiley \& Sons, Inc.

Jacobs, H.O. and Stemmer, A. (1999) Measuring and modifying the electric surface potential distribution on a nanometre scale: a powerful tool in science and technology, Surface and Interface Analysis, 27, 361-397

Jaworek, A. and Sobczyk, A.T. (2008) Electrospraying route to nanotechnology: An overview, Journal of Electrostatics, 66, 197-219

Jung, J.H., Park, S.Y., Lee, J.E., Nho, C.W., Lee, B.U., and Bae, G.N. (2011) Electrohydrodynamic nano-spraying of ethanolic natural plant extracts, Journal of Aerosol Science, 42, 725-736

Kim, H., Kim, J., Yang, H.J., Suh, J., Kim, T., Han, B.W., Kim, S., Kim, D.S., Pikhitsa, P.V., and Choi, M. (2006) Parallel patterning of nanoparticles via electrodynamic focusing of charged aerosols, Nature Nanotechnology, 1, 117-121

Kim, K., Kim, W., Yun, S.H., Lee, J.H., Kim, S., and Lee, B.U. (2008) Use of an electrospray for the generation of bacterial bioaerosols, Journal of Aerosol Science, 39, 365-372

Krinke, T.J., Fissan, H., Deppert, K., Magnusson, M.H., and Samuelson, L. (2001) Positioning of nanometer-sized particles on flat surfaces by direct deposition from the gas phase, Applied Physics Letters, 78, 3708-3710

Kwok, D.Y. and Neumann, A.W. (1999) Contact angle measurement and contact angle interpretation, Advances in Colloid and Interface Science, 81, 167-249

Lee, H., You, S., Woo, C.G., Lim, K., Jun, K., and Choi, M. (2009) Focused patterning of nanoparticles by controlling electric field induced particle motion, Applied Physics Letters, 94, 053104

Lee, S.W., Liang, D., Gao, X.P.A., and Sankaran, R.M. (2011) Direct writing of metal nanoparticles by localized plasma electrochemical reduction of metal cations in polymer films, Advanced Functional Materials, 21, 2155-2161

Lenggoro, I.W., Lee, H.M., and Okuyama, K. (2006) Nanoparticle assembly on patterned "plus/minus" surfaces from electrospray of colloidal dispersion, Journal of Colloid and Interface Science, 303, 124-130

Lenggoro, I.W., Okuyama, K., De la Mora, J.F., and Tohge, N. (2000) Preparation of ZnS nanoparticles by electrospray pyrolysis, Journal of Aerosol Science, 31, 121-136 
Lo, A.K.F., Zhang, L., and Sievering, H. (1999) The effect of humidity and state of water surfaces on deposition of aerosol particles onto a water surface, Atmospheric Environment, 33, 4727-4737

Mogus-Milankovic, A., Gajovic, A., Santic, A., and Day, D.E. (2001) Structure of sodium phosphate glasses containing $\mathrm{Al}_{2} \mathrm{O}_{3}$ and/or $\mathrm{Fe}_{2} \mathrm{O}_{3}$ Part I, Journal of Non-Crystalline Solids, 289, 204-213

Naim, M.N., Abubakar, N.F., Iijima, M., Kamiya, H., and Lenggoro, I.W. (2010) Electrostatic deposition of aerosol particles generated from an aqueous nanopowder suspension on a chemically treated substrate, Japanese Journal of Applied Physics, 49 , $06 \mathrm{GH} 17$

Ozasa, K., Nemoto, S., Isoshima, T., Ito, E., Maeda, M., and Hara, M., (2008) Direct measurement of transfer functions in Kelvin probe force microscopy using artificially patterned surface potentials, Japanese Journal of Applied Physics, 47, 5630-5635

Park, J. and Moon, J. (2006) Control of colloidal particle deposit patterns within picoliter droplets ejected by ink-jet printing, Langmuir, 22, 3506-3513

Ranganath, S.H., Tan, A.L., He, F., Wang, C.H., and Krantz, W.B. (2011) Control and enhancement of permselectivity of membrane-based microcapsules for favorable biomolecular transport and immunoisolation, AIChE Journal, 57, 3052-3062

Rezvanpour, A., Lim, E.W.C., and Wang, C.H. (2012) Computational and Experimental Studies of Electrohydrodynamic Atomization for Pharmaceutical Particle Fabrication, AIChE Journal, 58, 3329-3340

Rotole, J.A. and Sherwood, P.M.A. (2001) Oxide-free phosphate surface films on metals studied by core and valence band X-ray photoelectron spectroscopy, Chemistry of Materials, 13, 3933-3942

Seinfeld, J.H. and Pandis, S.N. (1998) Atmospheric Chemistry and Physics: from Air Pollution to Climate Change, (pp. 464-469), John Wiley \& Sons, Inc.

Smith, D.P.H. (1986) The electrohydrodynamic atomization of liquids, IEEE Transactions on Industry Applications, 22, 527-535

Tammet, H., Kimmel, V., and Israelsson, S. (2001) Effect of atmospheric electricity on dry deposition of airborne particles from atmosphere, Atmospheric Environment, 35, 34133419

Taylor, G.I., and McEwan, A. D. (1965) The stability of a horizontal fluid interface in a vertical electric field, Journal of Fluid Mechanics, 2, 1-15 
Vazques, G., Alvarez, E., and Navaza, J.M. (1995) Surface tension of alcohol + water from 20 to $50{ }^{\circ} \mathrm{C}$, Journal of Chemical \& Engineering Data, 40, 611-614

Xie, J., Rezvanpour, A., Wang, C.H., and Hua, J. (2010) Electric field controlled electrospray deposition for precise particle pattern and cell pattern formation, AIChE Journal, 56, 2607-2621 


\section{Figure Captions}

Figure 1. A schematic diagram of aerosolization of liquid-phase nanoparticles, its deposition as charged aerosol $\left(\mathrm{SiO}_{2}\right.$ and $\mathrm{AgNO}_{3}$ salt $)$, and velocity measurement at various distances without deposition by additional heating. A-E, P, and Q are the points of velocity measurements. The stainless steel capillary tube is enlarged (x17). The experimental system is separated into two cases: Namely, the substrates are either connected or unconnected with the ground potential.

Figure 2. FE-SEM images of the metal surface before deposition of aerosols on the treated (left) and untreated (right) areas.

Figure 3. Raman spectra of the Al substrates before (untreated) and after (treated) the chemical treatment.

Figure 4. SEM images of the deposited particles on the treated area (left side) and untreated area (right side) in the presence of the dryer system based on silica gel beads surrounding a device under heat-addition, electrical grounding, and with a distance of 70 $\mathrm{mm}$ from the tip to the substrate.

Figure 5. SEM images of the deposited particles in the absence of the dryer system based on silica gel beads surrounding a device under heat addition, electrical grounding, and with a distance of $70 \mathrm{~mm}$ from the tip to the substrate: (a) treated area (left side) and untreated area (right side) (b) particle morphology after magnification (c) untreated area and (d) particle morphology from Fig. $6 \mathrm{~b}$ after magnification.

Figure 6. Images of the deposited particles in the absence of the dryer system based on silica gel beads surrounding a device, without heating, electrically grounded electrode on the (a) treated (left) and untreated (right) areas, (b) untreated area, (c) interface between the treated and untreated areas, (d) treated area around the interface after magnification, (e) particle-size distribution of the deposited particles from Fig. 6d after analysis using an image processing software. 
Figure 7. SEM images of the deposited particles in the absence of the grounding electrode: (a) treated area (left) and untreated area (right) (b) particle morphology after magnification, (c) untreated area and (d) particle morphology on the edge of a "cluster".

Figure 8. Illustration of self-assembled particles on the edge during aerosol deposition. The droplet size receded due to solvent evaporation. Charged droplets may be aggregated to create larger particles. The rate of evaporation is larger at the edge than in the center, which causes aggregation of most particles on the edge, like "coffee ring phenomenon".

Figure 9. SEM images of the deposited particles under heat addition, electrical grounding, and with a distance of $120 \mathrm{~mm}$ from the tip to the substrate: (a) treated area and (b) untreated area of a single substrate.

Figure 10. Number concentrations of the $\mathrm{SiO}_{2}$ particles deposited on the treated area, estimated from the integrated areas in the XRF spectra.

Figure 11. SEM images of the deposited particles in the presence of a grounding electrode. $\mathrm{SiO}_{2}$ particles without $\mathrm{AgNO}_{3}$ salt was used as a material source.

Figure 12. Numerical simulation of the electric fields in the vicinity of the substrate in the "macro" distance (left side), and "micro" distance $(<3 \mathrm{~mm})$ around the interface of the treated and untreated areas (right side).

Figure 13. Schematic diagrams showing the mechanism of particle deposition on the treated (T) and untreated (UT) substrates in the (a) presence and (b) absence of a dryer system based on silica gel beads. 


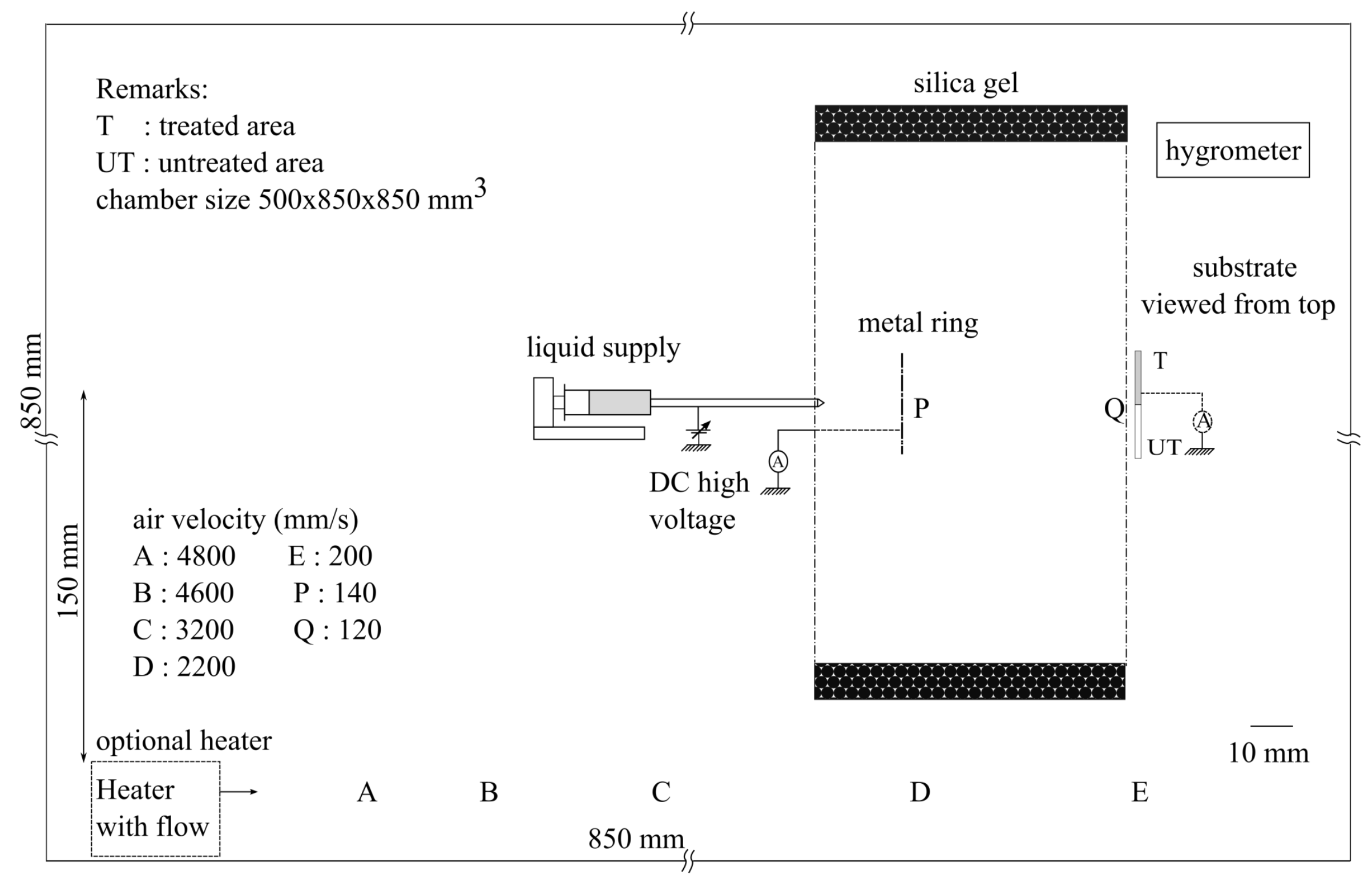


Fig. 2

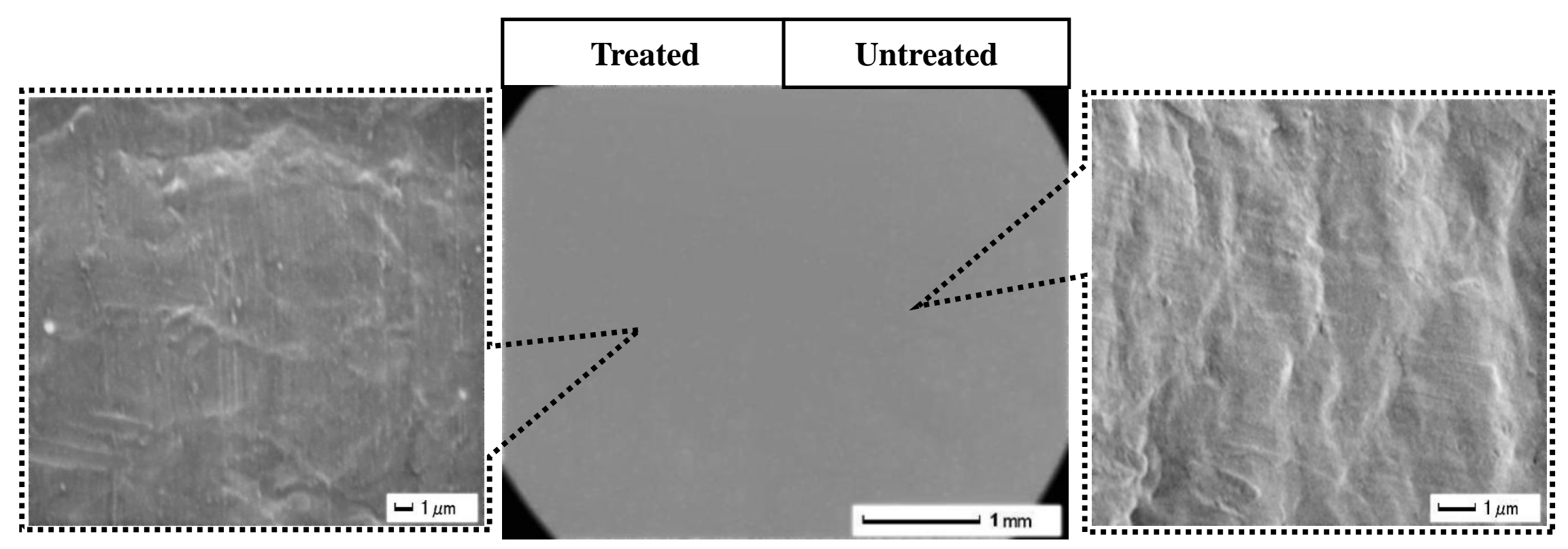


Fig. 3

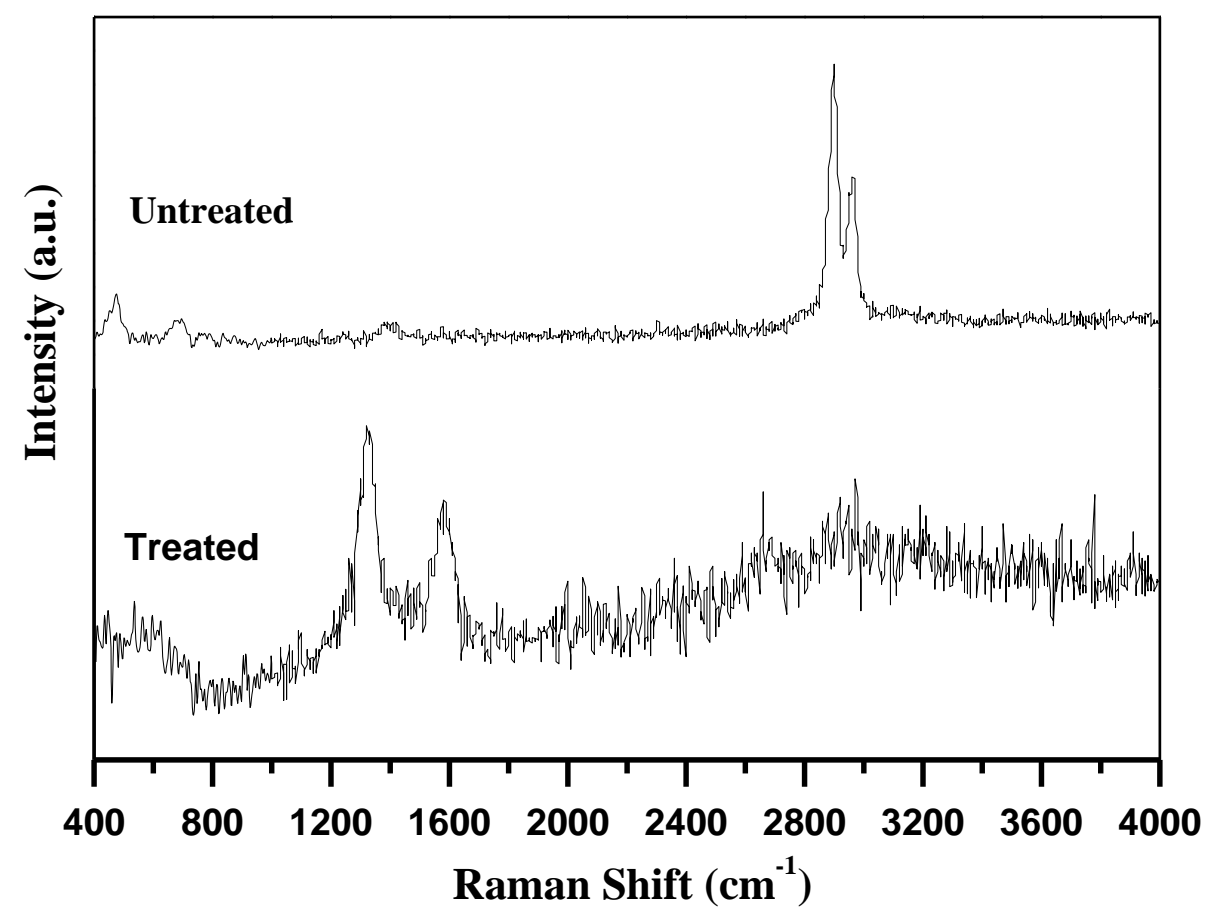


Fig. 4

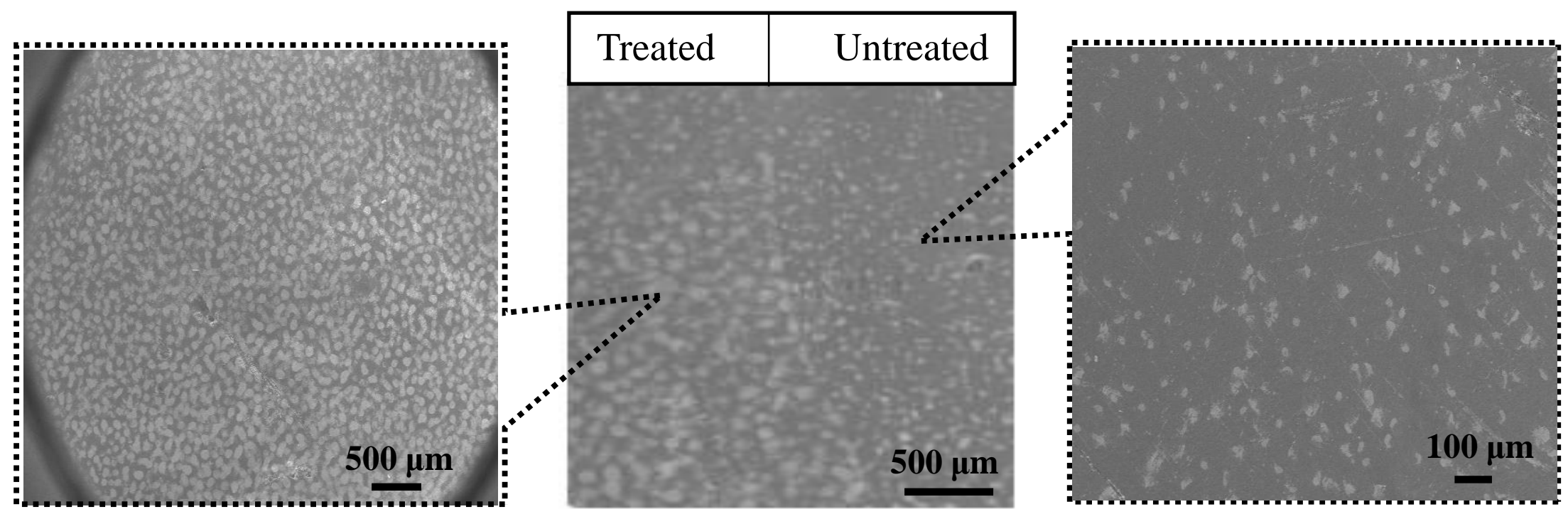


Fig. 5

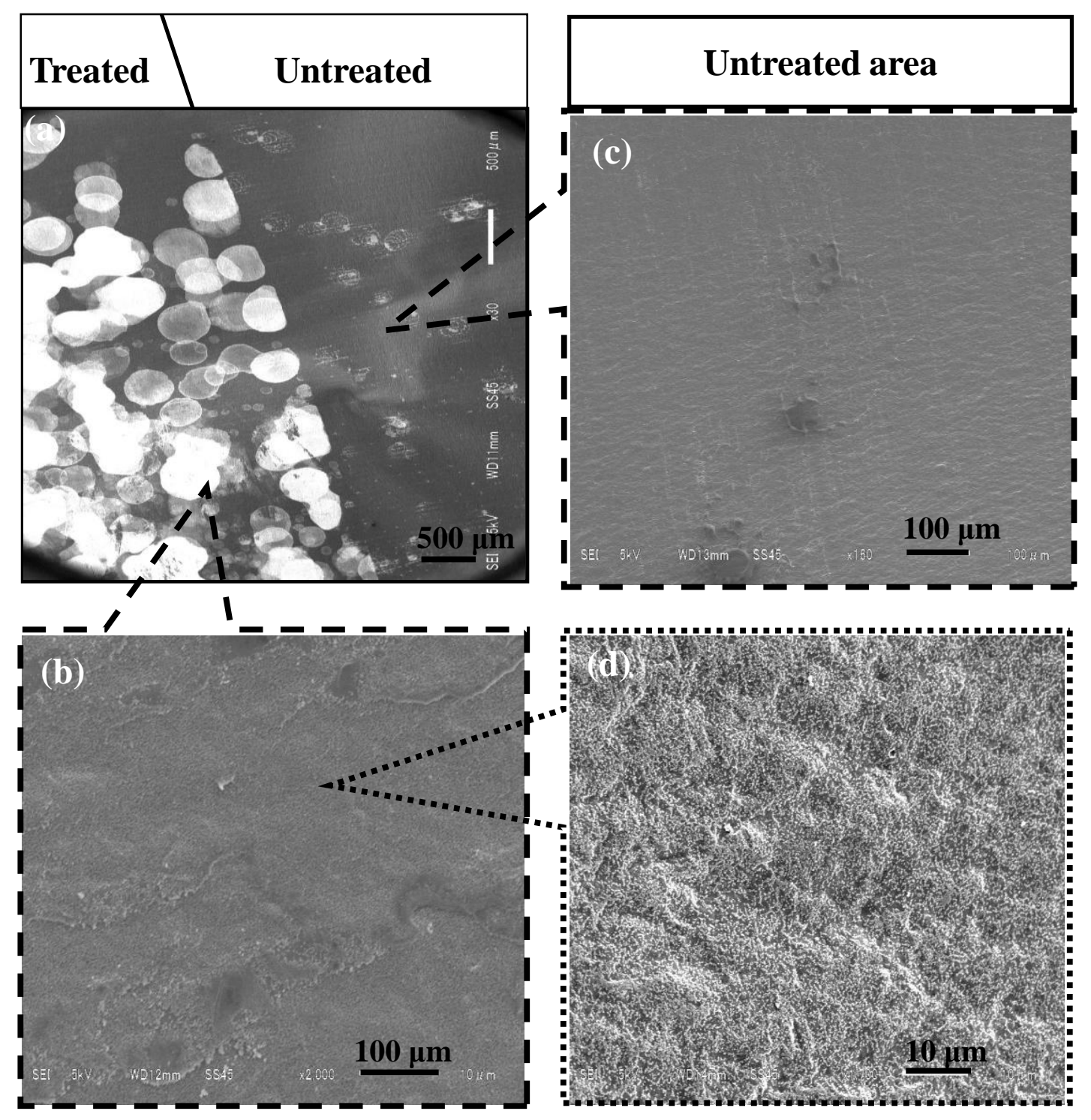


Fig. 6

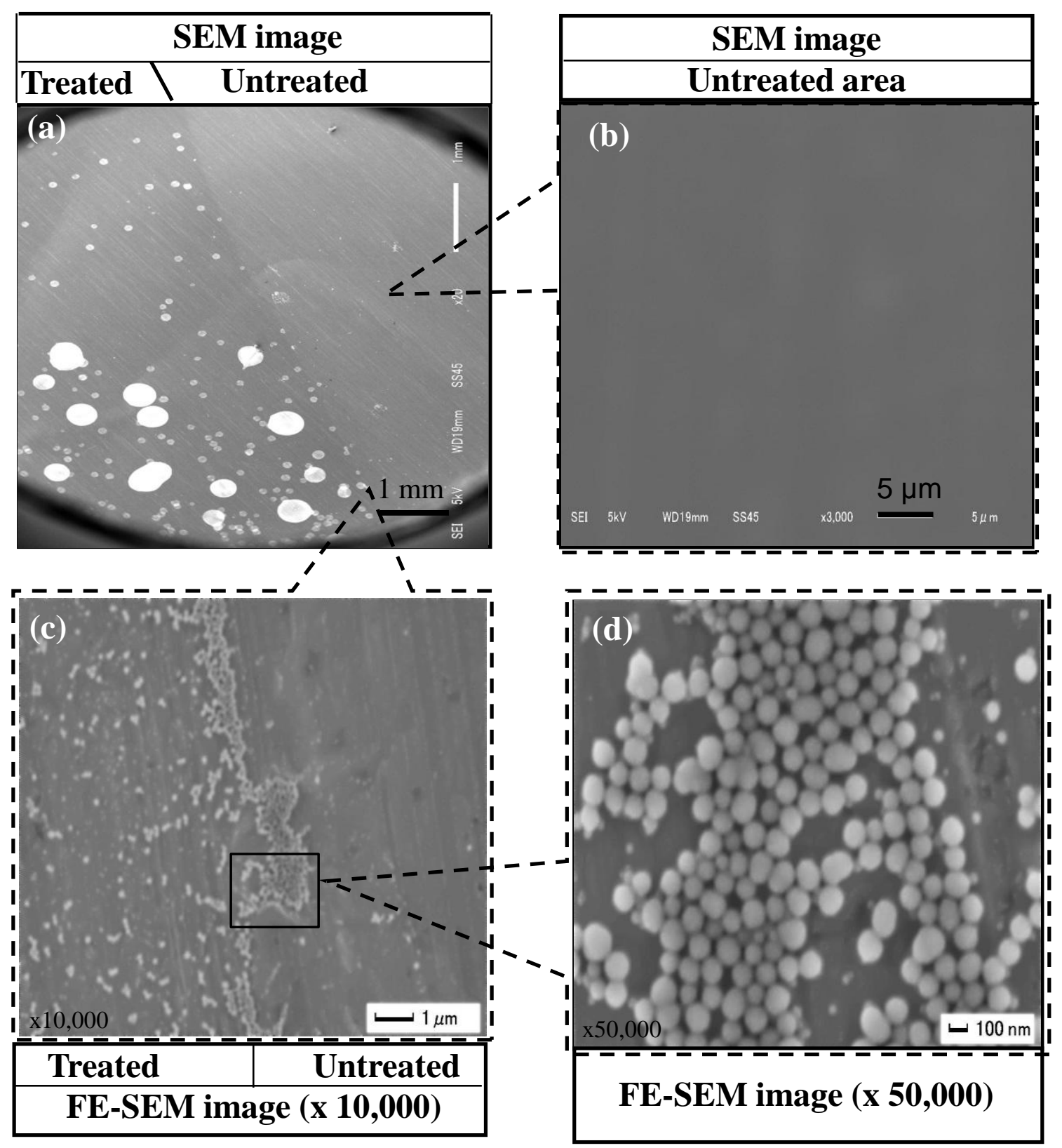


Fig. 6

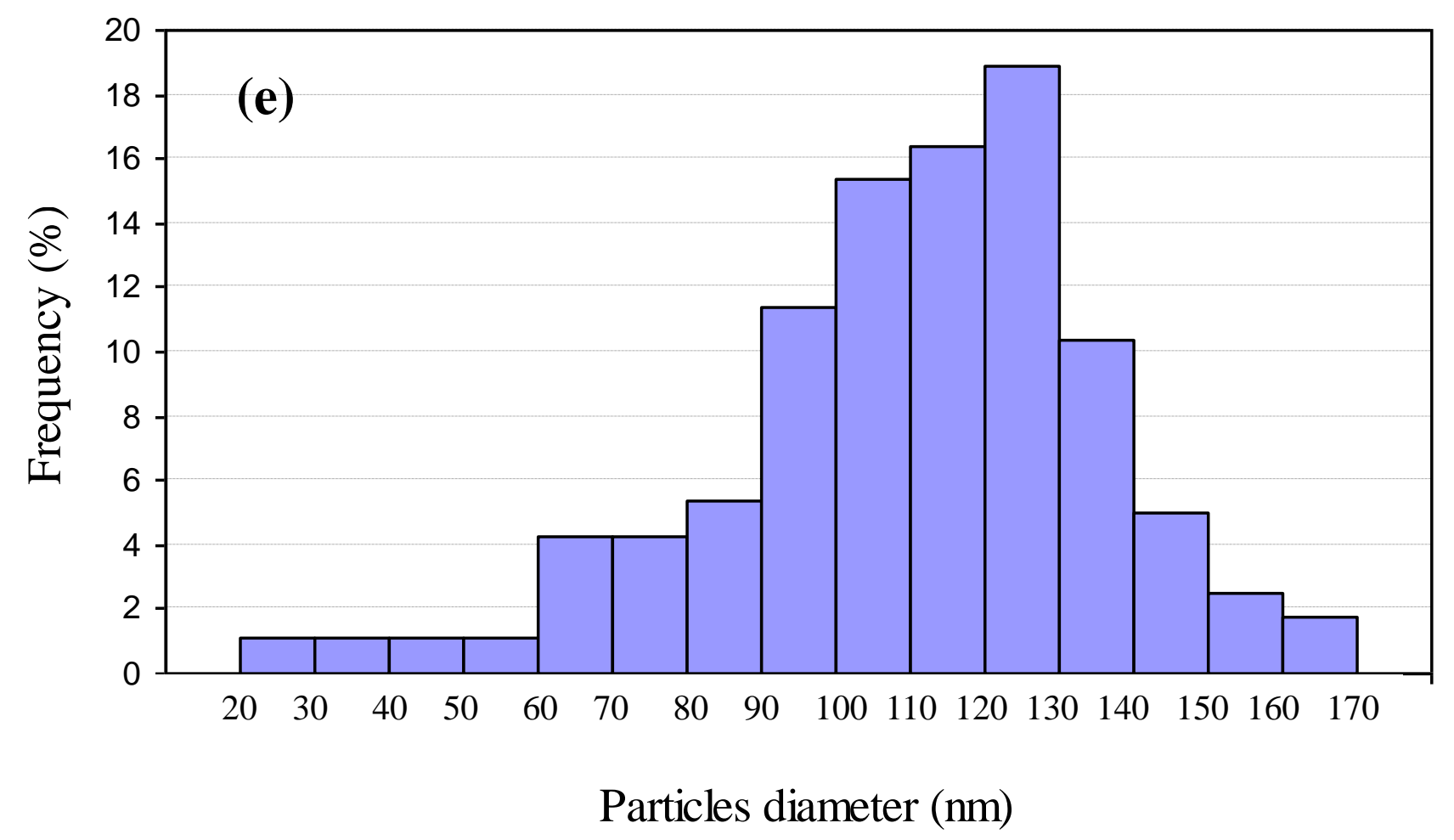


Fig. 7

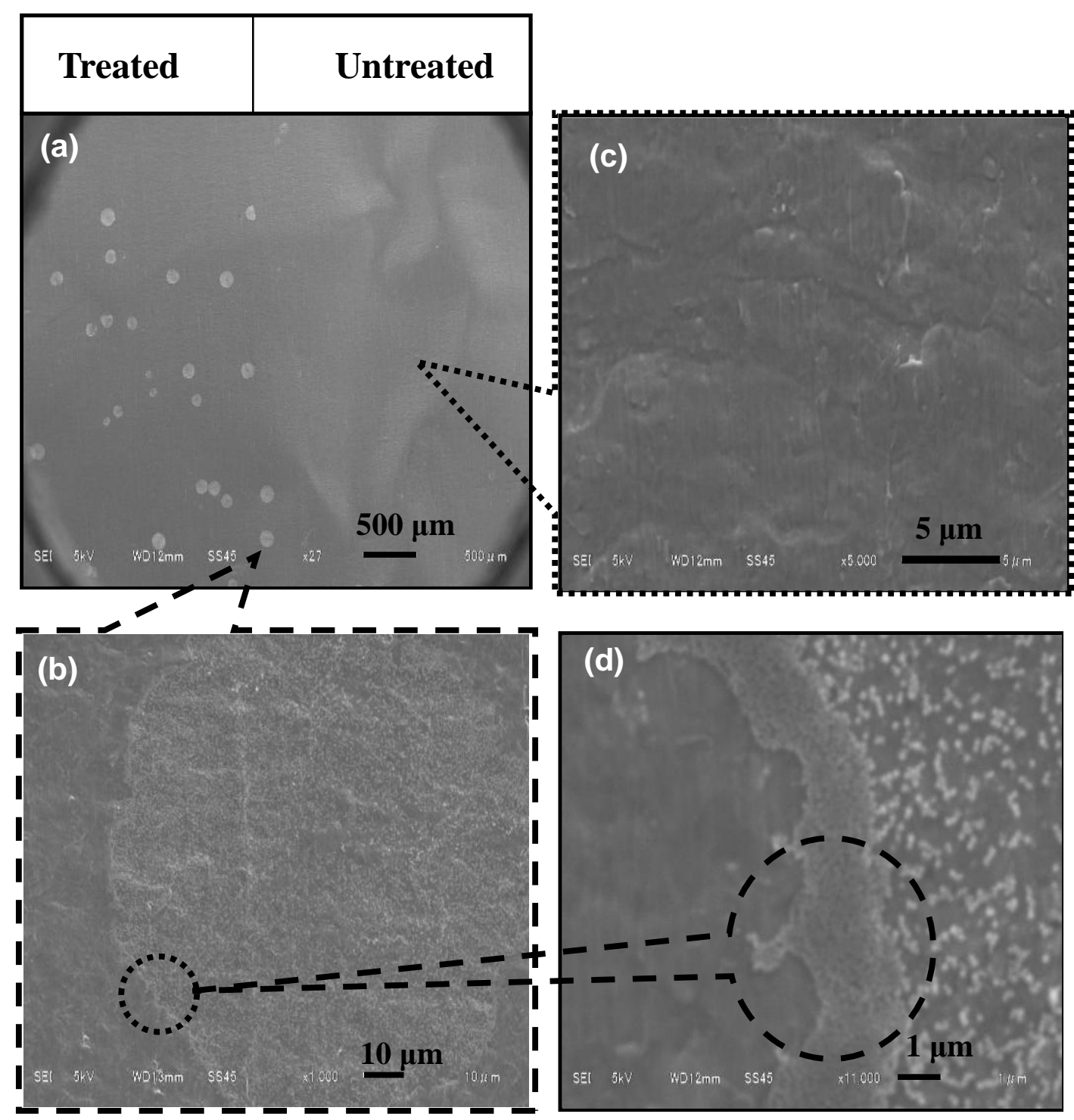


Fig. 8

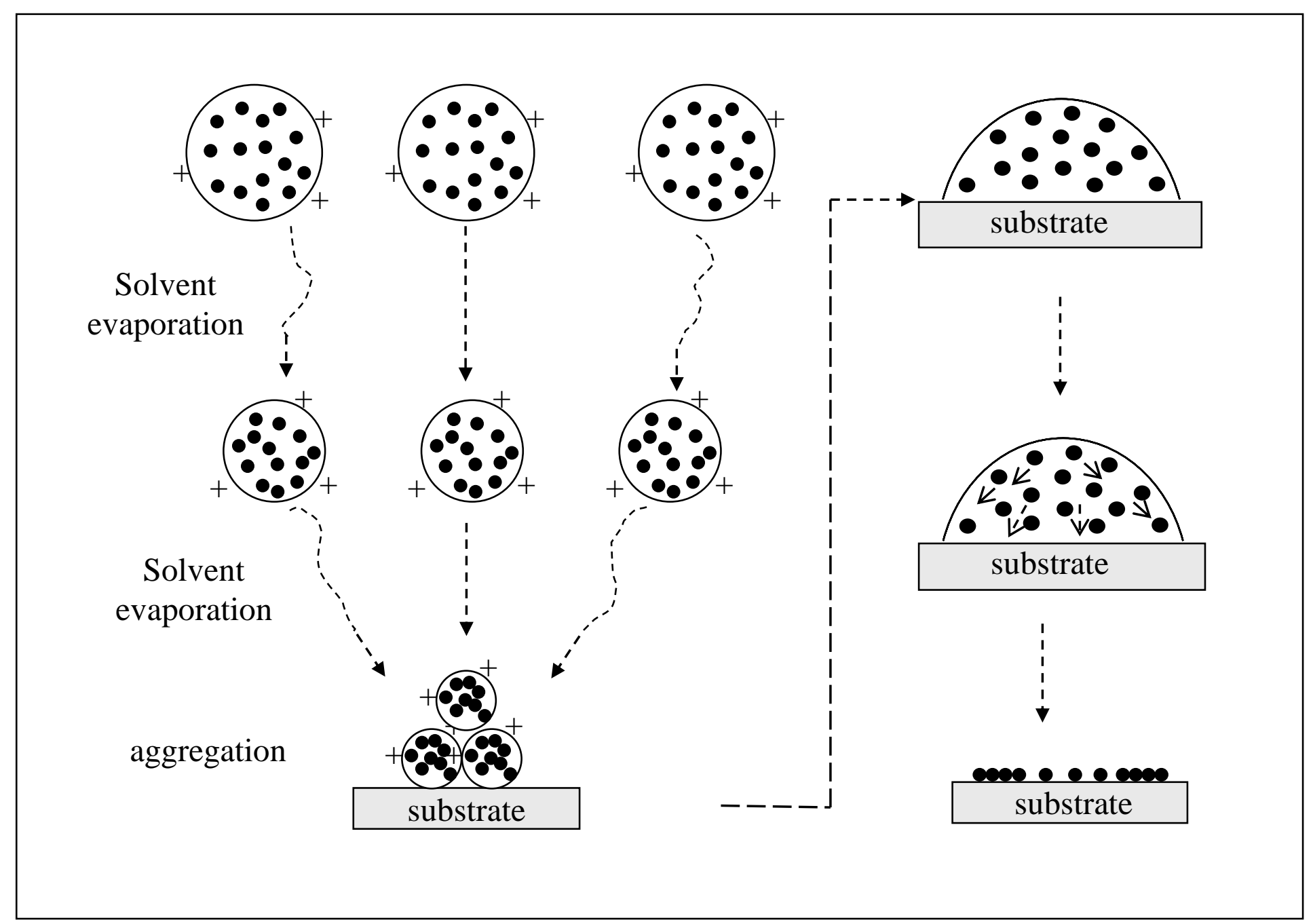


Fig. 9

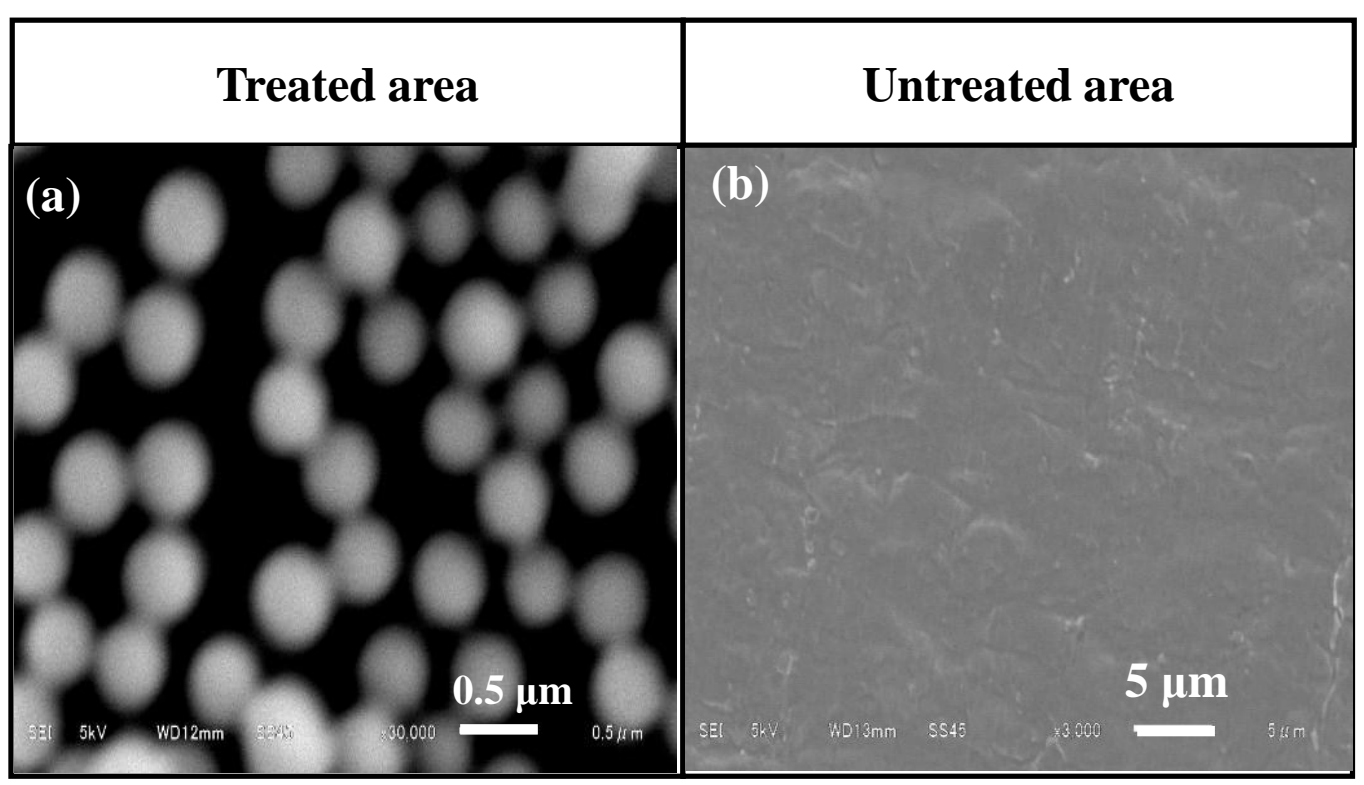


Fig. 10

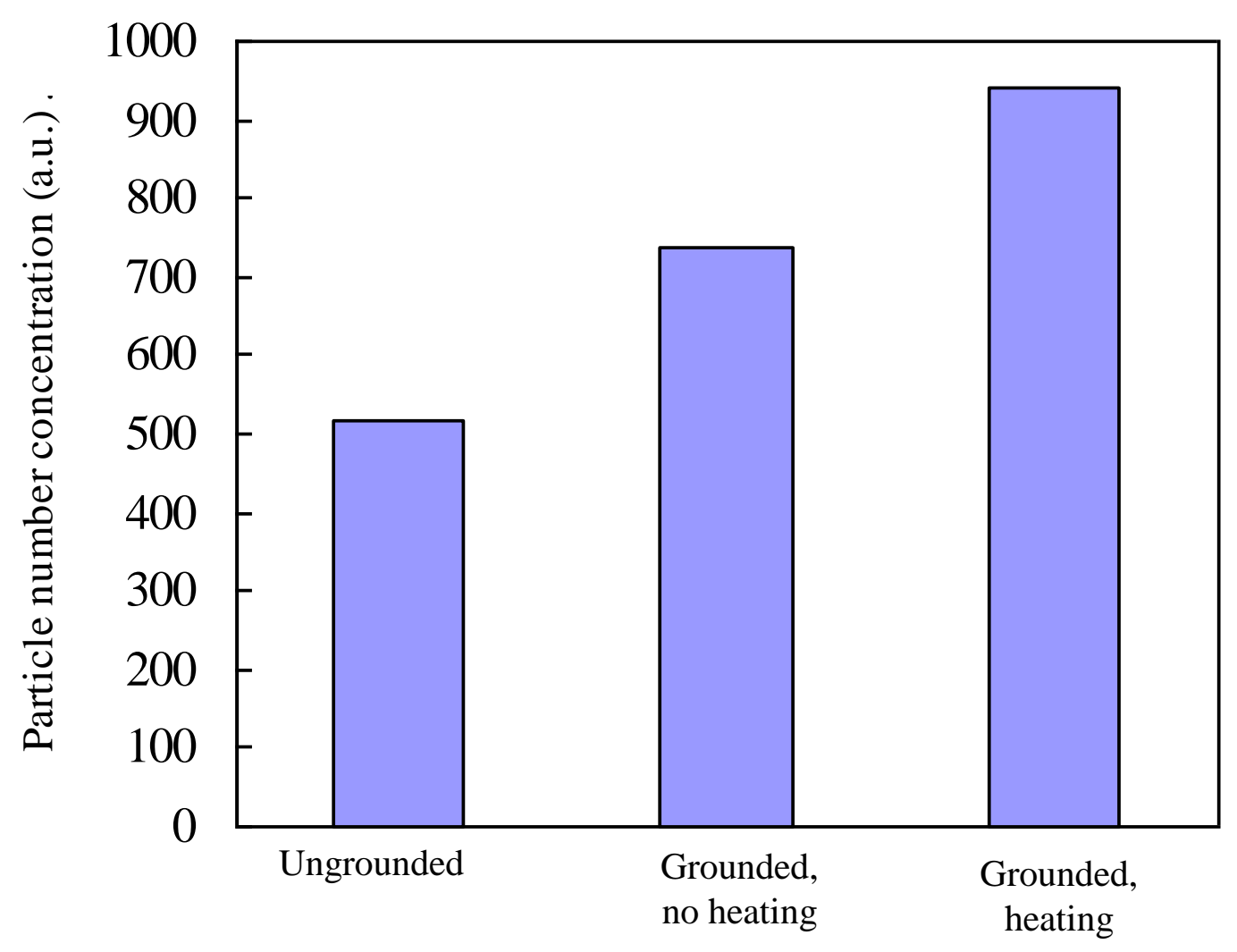


Fig. 11

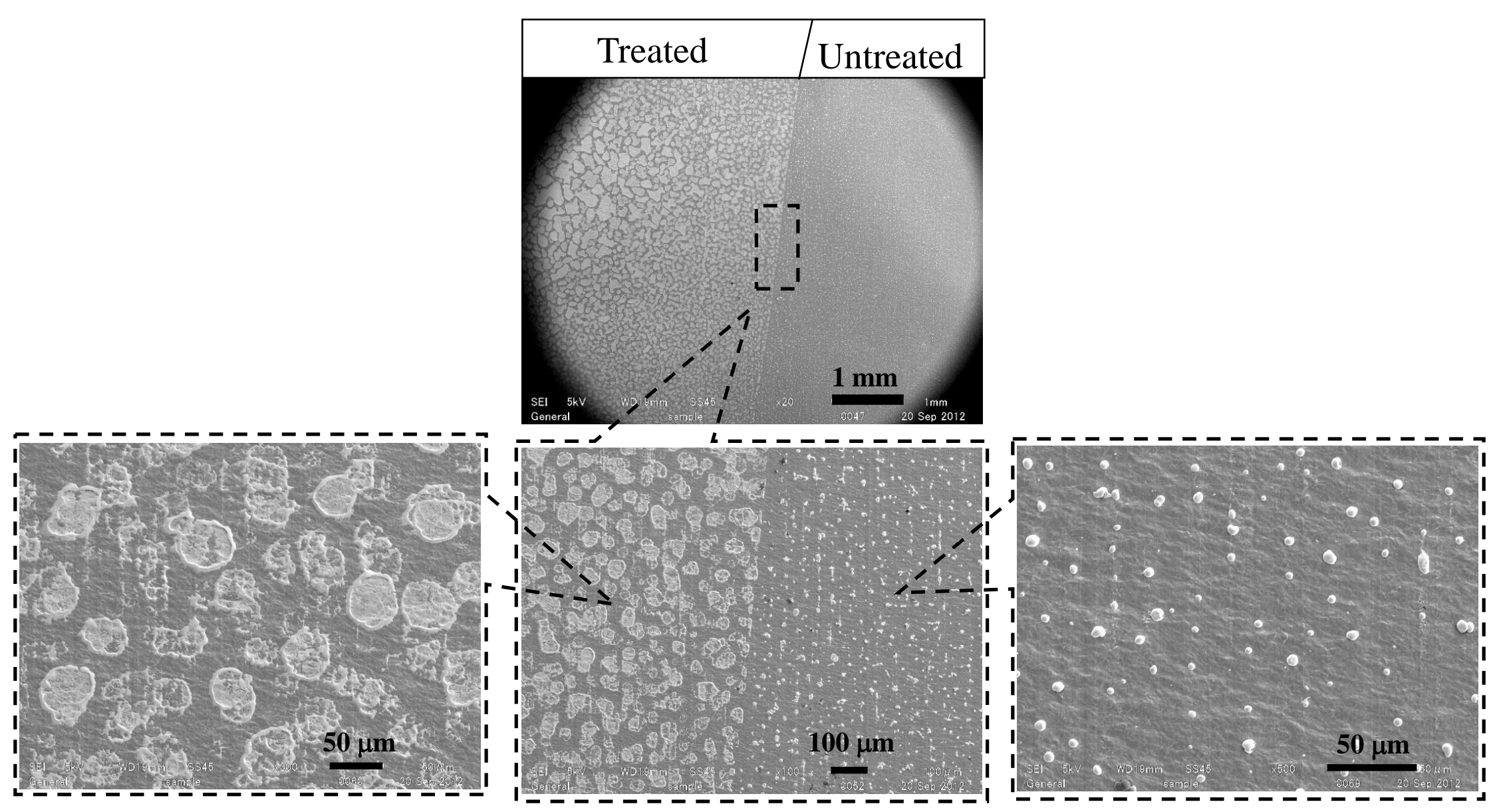


Fig. 12

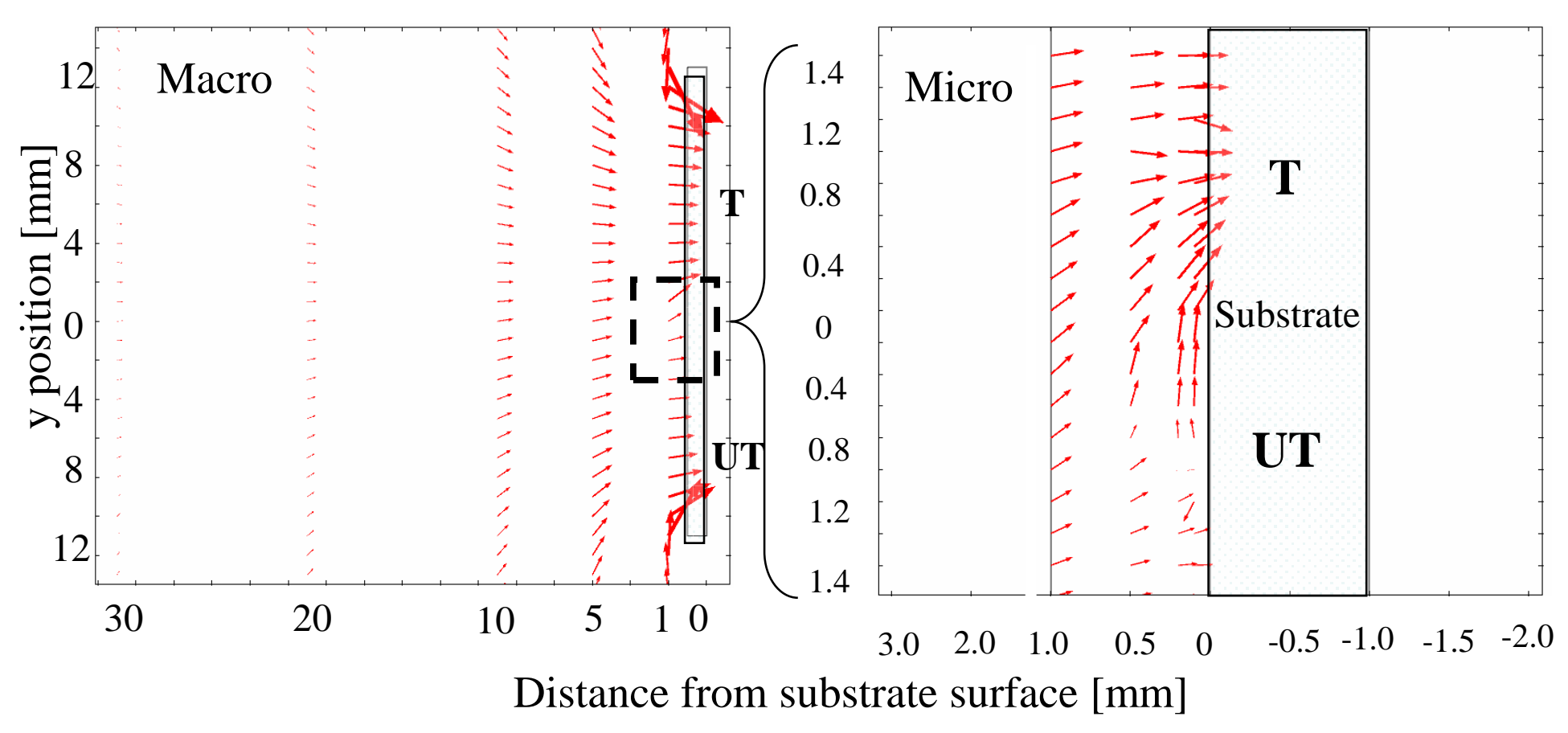


Fig. 13

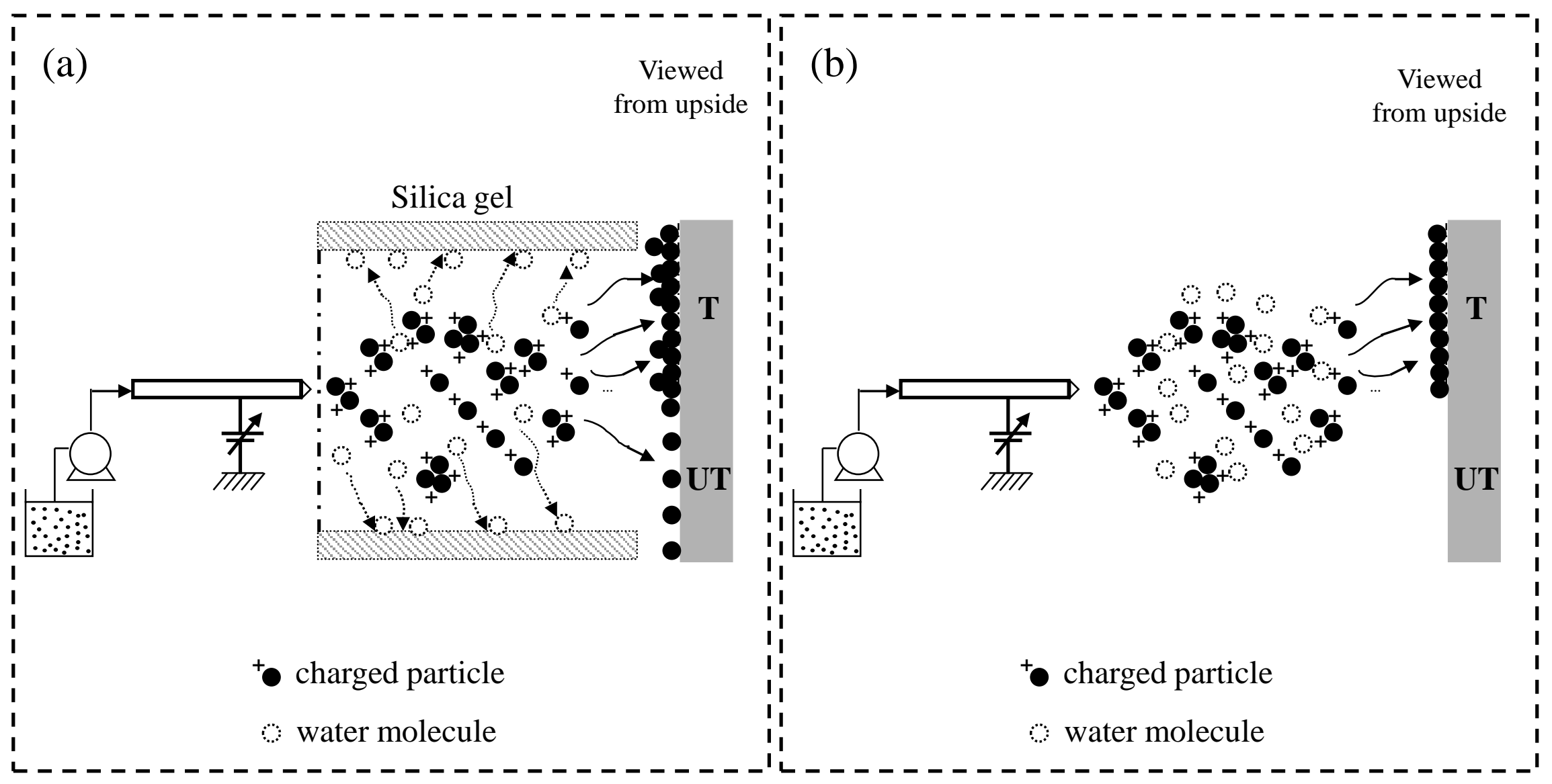




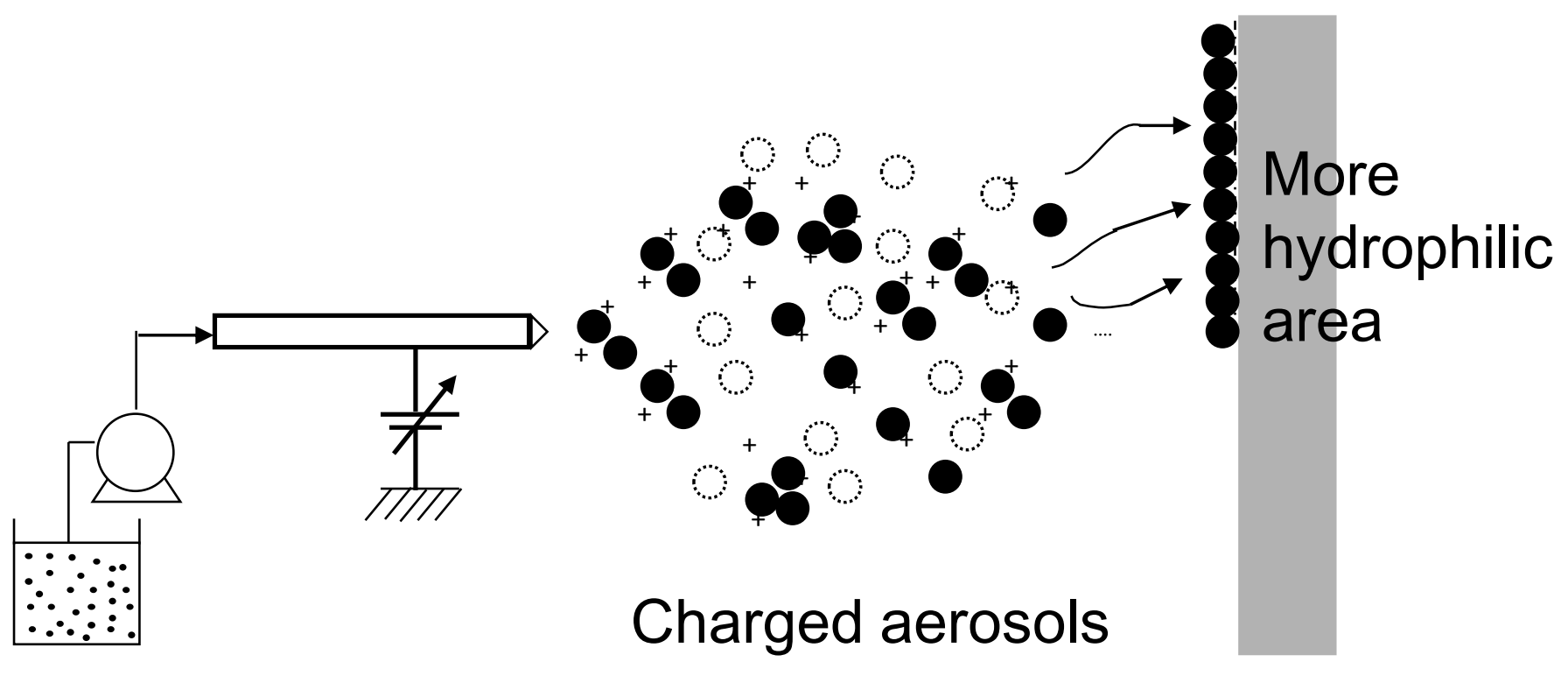

